\title{
Histopathological study of Effects of continuous injection of dexamethasone on wound healing in rabbits
}

\author{
F. Salim \\ Coll. of Vet. Med./ Univ of Basraha
}

\begin{abstract}
In this study 16 rabbit was divided in to two groups equally the first group was daily injected by dexamethasone $(1 \mathrm{mg} / \mathrm{Kg})$ for 21 days,the second group was left without any treatment as a control. An excision was made in the skin of rabbits and then sutured with silk band $2.5 \mathrm{~cm}$. The skin spicemen were taken for histopathological sections for wound healing evaluation at postoperative days 3,7and 14. The scars of the dexamethasone-treated group were less formation. The epithelization, collagenization and the inflammatory cell infiltration was less intense in the dexamethasone- treated group in compare with the control animal.
\end{abstract}

\section{Introduction}

Corticosteroid markedly effect most aspect of wound healing. Systemic administration of corticosteroid which is frequently used as non -specific antiinflammatory therapy in various diseases and traumas (1) may result in poor wound healing due to its catabolic effects in skin. The steroids reduce TGf- $\beta$ and IGF-I production in wounds and that collagen deposition suffers by that mechanism (2). Dexamethasone is a potent glucocorticoid with a continuous action level, due to its relative long biological half life (3654hours) .it has pleomorphic effect on the immune system and may inhibit epidermal apoptosis by several mechanism :inhibition of T-cell activated apoptosis by

\section{Materials and methods}

Experiments were conducted on 16 local rabbits weighing 1300-1700g, they were randomly assigned to two groups of eight animals, the first group was daily injected with dexamethasone $(0.1 \mathrm{mg} / \mathrm{Kg})$ for 21 days, intraperitoneally (IP) and the second group was left without any treatment as the control group. In a temperature-controlled and ventilated room with a 12-h light-dark cycle, animals were housed for at least 10 days before experiments and were given unlimited access to food and water. On the22th day, after anesthesia was induced with ketamin $(15 \mathrm{ml} / \mathrm{kg})$ and Xylazine $(5 \mathrm{ml} / \mathrm{kg})$ intramuscularity (I.M), an excision was made in the dorsal midline of abdomin.Wound healing was evaluated at postoperative days 3,7 and 14 . On the suppression of various cytokines such as TNF- $\alpha$;inhibition of interferon $-\gamma$ induced apoptosis; and inhibition of Fas-mediated keratinocyte apoptosis.(3). Dexamethasone reduce the number of cells in DNA synthesis and post wounding acanthosis of wound edge and regenerating epithelium (4). Dexamethasone has anti inflammatory effects and has been used during operation for decreasing edema formation and swelling and for preventing ischemiareperfusion injury. Chronic or inappropriate use of dexamethasone can cause life threatening hormonal and metabolic changes(5).The aim of this study is to investigate the effect of chronic use of dexamethasone on skin wound healing.

experiment day, The rabbit hair was closely shaved with an electrical razor, and the surgical field was disinfected with povidone-iodine and draped with sterile towels. All surgical procedures were performed under aseptic conditions . An incision, measuring approximately $5 \mathrm{~cm}$, was made through the skin of each animal until the muscular fascia was exposed. Then the wound margins were opposed with a non absorbable interrupted suture. No postoperative antibiotics were given.On the 3,7 and 14th day, the wounded area was cut into a $5 \times 1 \mathrm{~cm}$ strip under anesthesia. For histopathologic examinations, the biopsies were placed in $10 \%$ formaldehyde, embedded in paraffin, sectioned perpendicular to the wound, and stained with hematoxylin-eosin. 
Histopathologic samples were examined

During the observation period no animal died in control or dexamethasone groups.On the third day post operative in control animal there was thickness of wound epidermis,early inflammatory response characterized by abundance of neutrophils at the wound gap, a number of fibroblast can be seen in the dermis as in figure(1), while in dexamethasone group there is a dermal thickness, epidermal thickness was moderate with ulceration area with Carter like.The Carter has small diameter rich with inflammatory cells extending deep in the dermis like stream as in (Figure2). In the $7^{\text {th }}$ day post operative control animal there was epithelization with new capillaries in the granulation by using light microscope.

\section{Result}

tissue with marked collagenization (figure3), dermal fibrosis, fibrosis between skeletal muscles with an area of ulceration in the dexamethasone group were noted. In control animal the blood vessels was less with great collagenization scab formation, and begin of epidermal epithelial regeneration (Figure4). On the $14^{\text {th }}$ day post operative in dexamethasone group there is epidermal thickness, fibrosis ,reduce diameter size of ulcer with decrease rate of inflammation(figure5) ,more fibrosis and keratosis(figure6). In control animal the blood vessels is less with great collagenization and epithelization.

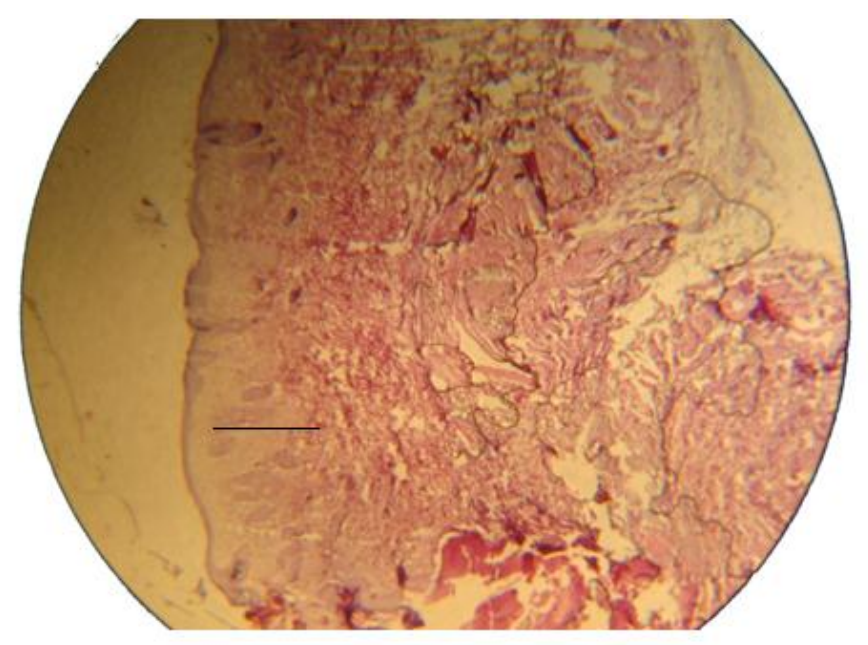

Figure1:Section of skin in control group after 3days,note thickness of epidermis rich with inflammatory cells.X10(H\&E) 


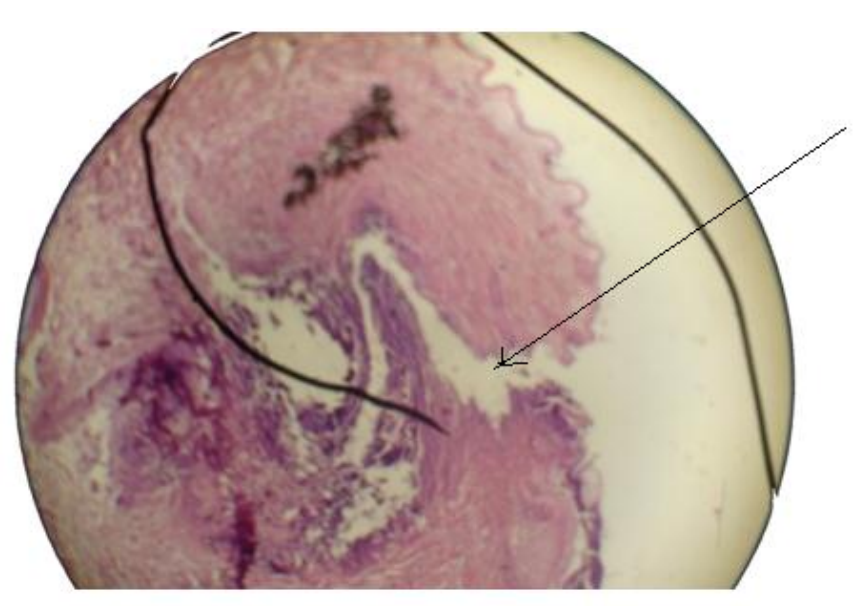

Figurer 2: Show the skin in dexamethasone group after 3days, note ulceration and Carter -like .X4 (H\&E).

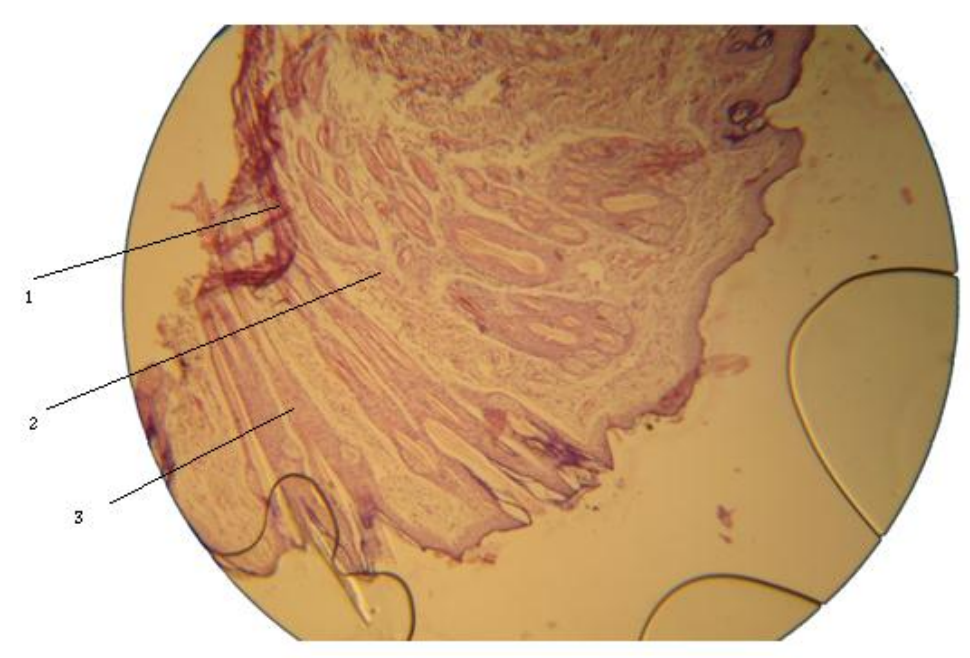

Figure3: Skin of control group after 7days, note scab formation (1), fibrosis (3), regeneration epidermal epithelial (2) .x10 (H\&E). 


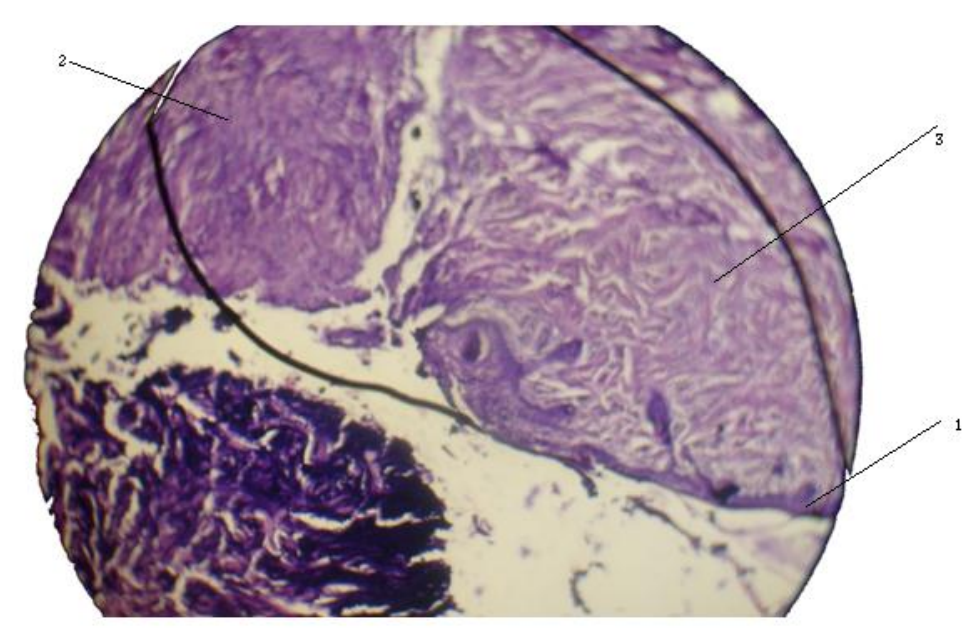

Figure4: skin of dexamethasone group after 7days, note scab formation(1), fibrosis(2), regeneration of epidermal epithelial (3).x10 (H\&E).

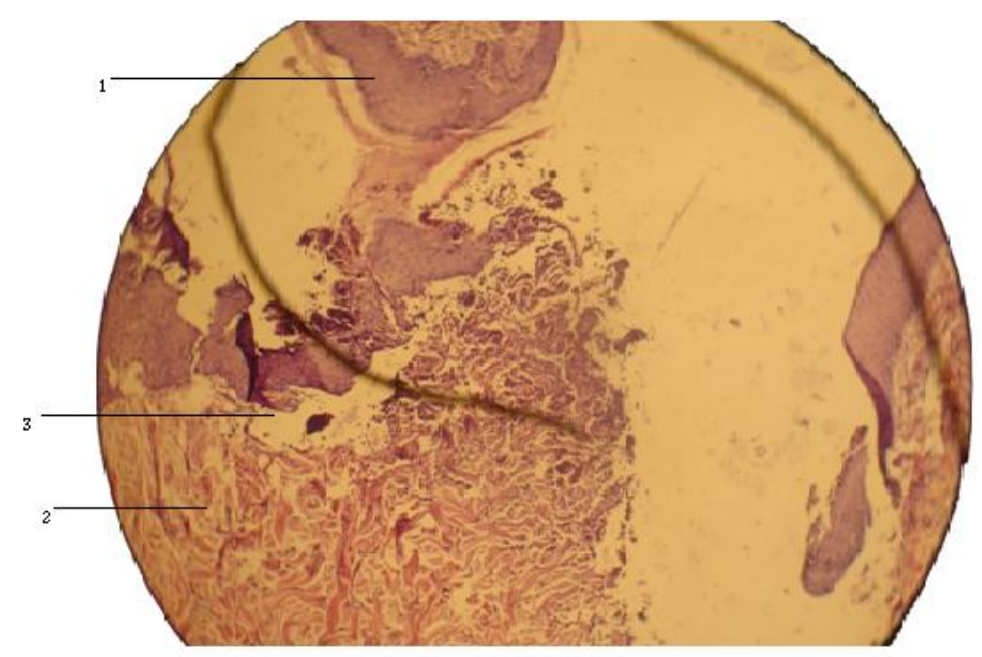

Figure5: Skin of dexamethasone group after 14days,note thick epidermis(1), fibrosis(2), reduce diameter size of ulcer(3) \&decrease rate of inflammation.X10(H\&E). 


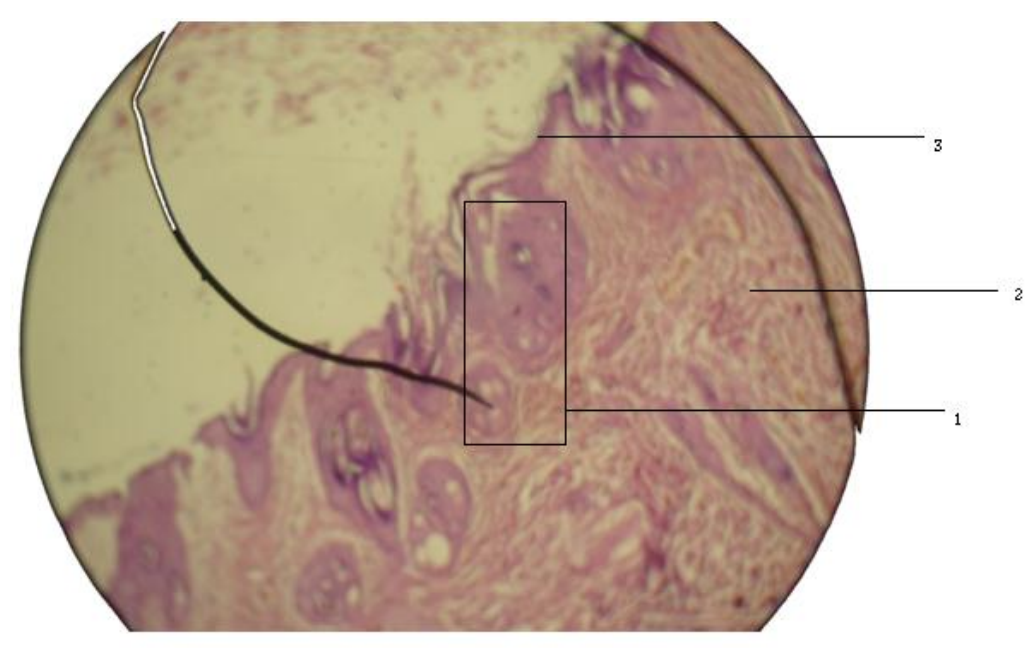

Figure6: Skin of dexamethasone group after 14days,note thick epidermis(1) ,more fibrosis(2), hyper keratosis(3).X10(H\&E).

\section{Discussion}

The result of this study reveals thickening with epidermis with inflammatory cells in 3 days, developed to angiogenesis and epithelization with in the 7th days in control animal decrease the blood vessels number with great collagenization and scab formation in $14^{\text {th }}$ day post operative. The wound healing process has been divided in to three phases: inflammation, proliferation and remodeling, however, the process is continuous and phases overlap (6). The fibrin clot is replaced by blood vessels, rich granulation tissue replaced by scar formation $(7,8)$. In dexamethasone group there is decrease in inflammation and this is agree with previously published studies $(9,10)$ and contrast with (11) who found that corticosteroids-induced increased number of macrophage and impaired process of re-epithelization as glucocorticoid-inhibited keratinocyte growth process (12) .Cortisone and other anti inflammatory steroid increase the integrity of the lysosome, lysosomal enzymes are known to take prominent parts in the inflammation.In 7days post operative group treated with dexamethasone there is clear negative effect of dexamethasone on granulation tissue due to decrease process of neoangiogenesis and this is agree with study of (13)who found that daily injection of dexamethasone inhibited a basal sponginduced angiogenesis. (14) found that corticosteroid decreased expression of transforming growth factor and B(TGF_B) and exogenous administration of this factor improved wound healing (15).Following damage to skin ,the enhanced synthesis and secretion of extracellular matrix proteins by smooth muscle $\alpha$-expressing myofibroblasts play a fundamental role in scar formation and healing $(16,17,18)$. Corticosteroid therapy during the acute phase following coronary artery ligation lead to impaired scar formation $(19,20)$. Glucocorticoids are potent antiinflammatory agents that inhibit leukocyte adhesion and aggregation (21) and decrease the expression of several cytokines like monocytes $(22,23,24)$, interleukin-1(IL-1) (25) and interleukin6(IL-6) (26). They have a strong antiproliferative effect and are able to inhibit SMC proliferation (27,28).In 14 day postoperative system the corticosteroids decrease extracellular matrix deposition and remodeling because its ability to decrease collagen synthesis (29). 


\section{References}

1. Brans Y,Dweck H,Harris H,et al.( 1981). Effect of open-heart surgery on the body composition of infants and young children .Pediatric Res; 15:1024-8.

2.Wicke C, Halliday B., Allen D, et al. (2000). Effect of steroid and retinoids on wound healing .Arch Surg;135:1265-70.

3.Nesbitt T., (1995). Minimizing complications from systemic glucocorticosteroid use. Dermatologi Clinic;13:925-939.

4.Devitt H,Clark M.,Marks R.,Picton W. (1978). Aquantitive approach to epidermal wound healing:the effect of dexamethasone on regenerating epithelium .British J of Dermatology : 1365-2133.

5.Askar I,Bozkurt M.( 2002).Protective effects of immunosuppressants and steroids against ischemiareperfusion injury in cresmaster muscle flap at microcirculatory level.Microsurgery;22:361-6

6.Drucker M, Cardenas E, Azitri P, Valenzuela A. (1998). Experimental -studies on effect of lidocaine on wound healing. World J Surg;22:394-8.

7.Clark RA,Langian JM,DellaPelle P,et al.( 1982).Fibronectin and fibrin provid a provisionalmatrix for epidermal cell migration during wound reepithelization.J Invest dermatol;79:264-9.

8.Welch MP,Odl and GF, Clark RA. (1990).Tempolar relationships of Factin bundle formation, collagen and fibronectin assembly , and fibronectin receptor expression to wound contraction..J Cell Biol;110:133-45.

9.Leibovich S.J;ross R.(1975).Therole of macrophage in wound repair.A study with hydrocortsoneand antimacrophage serum.American Journal of pathology.78,71-100.

10. Anstead G.M. (1998). Steroid, retinoids, and wound healing. Advances in skin and wound care, 11,277-285.

11. Gal P., Kilik R,MOkry M. (2008). Simple method of open skin wound healing model in corticosteroid - treared and diabetic rats: standardization of semi-quantitative and quantitative histological assessments. Veterinarni Medicina, 53, (12): 652659.

12. de Duve,C.,(1964).Lysosome and cell injury. In International Symposium on injury, inflammation and immunity. Edited by L.Th omas et al, Baltimore, p.283

13. Chedid M.,Hoyle J.Csaky K,Rubin J(1996):Glucocorticoids inhibit keratinocyte growth factor production in primary dermal fibroblasts.Endocrinology,137,2232 $-2237$.

14. Hori Y.,Hu D., Yasui K.,smither R.,Gresham G..Fan T. (1996) Differential effect of angiogensis and cytokine level in rat sponge implants .British Journal of pharmacology, 118, 1584-1591.

15. Frank S., Madlener M.,Werner S., (1996):Transforming growth factors beta 1,beta2,beta3 and their receptors are differentially regulated during normal and impaired wound healing Journal of Biological chemistry, 271, 10188-10193.

16. Beck L.,DeGuzman L.,Lee W.,Siegel M., Amento E. (1993).One systemic administration of transforming factor beta 1 reverses age-or glucocorticoid-impaired wound healing Journal of clinical Investigation.,92,2841-2849.

17. Hasan W,Zhang R,Liu M, Warn JD, Smith PG. (2000).Coordinate 
expression of NGF and $\alpha$-smooth muscle actin mRNA and protein in cutaneous wound tissue of developing and adult rats .Cell Tissue Res 300:97-109.

18. Liu M, Warn JD, Fan Q Smith PG, (1999).Relationship between nerves and myofibroblast during cutaneous wound healing in the developing rat.Cell Tissue Res. 297:423-433.

19. Sun Y,Weber KT.Infarct scar :a dynamic tissue. (2000). Cardiovasc Res46:250-256.

20. Sholter DE, Armstrong PW. (2000). Adverse effect of corticosteroid on the cardiovascular system. Can J Cardiol 16:505-511.

21. Bulky BH,Robert WC.(1974)Steroid therapy during acute myocardial infarction .Acause of delayed healing and of ventricular aneurysm.Am J Med 56:244-250.

22. Constein B., Kimmel S.Levin R. Martiniuk F.,Weissmann G.A . (1992). mechanis for the antiinflammatoryeffect of corticosteroids:the glucocorticod receptor regulates leukocyte adhesion to endothelial cells and expression of endothelial-leukocyte adhesion molecule 1.Proc Natl Sci U S A .89:9991-9995.

23. Nichols N.,Olsson C.FunderJ. (1983).Steroid effects on protein synthesis in cultured smmoth

$\begin{array}{lr}\text { muscle cells } & \text { from rat } \\ \text { aorta.Endocrinology } & 113: 1096- \\ 1101 & \end{array}$

24. Suzuki T.,Kopia G.Hayashi S.,Baily L. et al.(2001).Stent based delivery of sirolimus reduces neointimal formation in a porcine coronary model.Circulation 104:1188-1193.

25. Poon M.Gertz S.,Fallon J.,Wiegamn P., et al. (2001). Dexamethasone inhibits macrophage accumulation after ballon arterial injury in cholesterol fed rabbits. Atheroseclerosis155:371-380.

26. Marmur J, Poon M, Rossikhina M.,Taubman M. (1992).Indution of PDGF-reponsive genes in vascular smooth muscle. Implications forearly response to vessels injury.Circulation. The American Journal of Cardiology.68:53-60

27. Lee S..Tsou A.,Chan H.,Thomas J., Petrie K,et al. (1988). Glucocorticoids selectively inhibit yhe transcription of the interleukin 1 beta mRNA.Poc Natl Acad Sci U S A.85:1204-1208.

28. Reil T.,Sarkar R.,Kashyap V., Sarkar.,Gelabert H. (1999). Dexamethasone suppresses vascular smooth muscle proliferation.J surg Res .85:109-114.

29. Krane S.,Amento E. (1984). Glucocorticoids and collagen diseases.Adv Exp Med Biol .171:61-71.

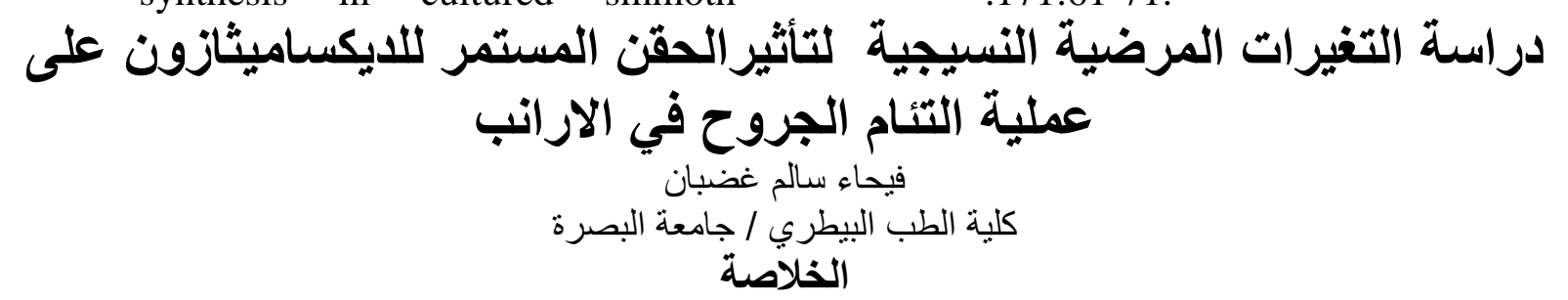

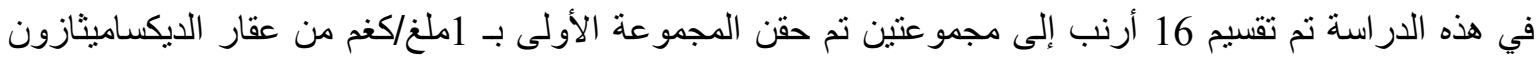

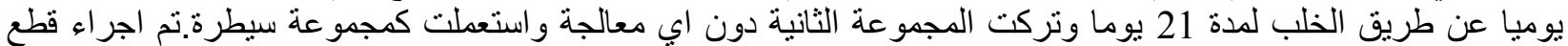

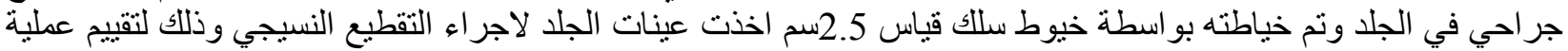

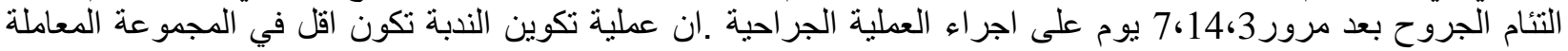

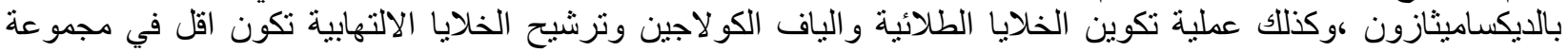
المعالجة مقارنة مع مجمو عة السيطرة. 